\title{
A educação do futuro: uma reflexão sobre aprendizagem na era digital
}

\author{
Pasqueline Dantas Scaico ${ }^{1,2}$, Ruy José Guerra Barretto de Queiroz ${ }^{1}$ \\ ${ }^{1}$ Centro de Informática (CIn) - Universidade Federal de Pernambuco \\ ${ }^{2}$ Centro de Ciências Aplicadas e Educação (CCAE) - Universidade Federal da Paraíba \\ \{pds, ruy\}@cin.ufpe.br
}

\begin{abstract}
This paper presents a reflection about future education and the influence of technology to a new learning culture. Instead of accumulating information, young learners need to know how to solve problems and be creative in a changing world. Discuss the digital era phenomena and how to explore technological use is relevant so we can think new conceptions about the education we want for the youth's future.
\end{abstract}

Resumo. Este artigo apresenta uma reflexão sobre a educação do futuro e a influência das tecnologias para uma nova cultura da aprendizagem. Mais do que acumular informações, os jovens precisam aprender a resolver problemas e serem criativos em um mundo em constante mudança. Discorrer sobre os fenômenos que ocorrem na era digital e como canalizar o uso de tecnologias é algo relevante para que possamos repensar novas concepções sobre a educação que queremos para o futuro da juventude.

\section{Introdução}

Espera-se no futuro que as pessoas sejam dotadas de novas competências para que possam enfrentar o ritmo acelerado de constantes transformações. O pensamento crítico, a capacidade de análise e de interpretação e a aprendizagem adaptativa são algumas das competências esperadas para o século XXI. Será necessário também desenvolver melhor a nossa inteligência fluida, que é um processo de perceber relações, formar conceitos, se adaptar, utilizar-se do raciocínio lógico e da abstração (Lopes et al, 2012).

$\mathrm{Na}$ sociedade do conhecimento o saber está assumindo outra dimensão que atravessa o conhecimento explícito e atinge o conhecimento tácito. Para a sociedade do futuro não bastará apenas deter conhecimentos. É preciso que sejamos capazes de agir diferente e de assumir outras posturas. Essas transformações, claramente, afetarão os nossos sistemas de educação e demandarão às escolas novos espaços e cenários de aprendizagem. Todavia, antes de imaginar qualquer mudança, precisaremos de uma reforma de pensamento.

Entre outras tantas coisas, deveremos tomar consciência de que as tecnologias serão um instrumento importante para permitir que cada indivíduo aprenda a gerir o seu próprio processo de aprender, em uma tentativa de assegurar o arco de aprendizagem até a vida adulta, quando nessa etapa a escola não mais estará presente para sustentar o processo instrucional. As possibilidades que existem hoje para aprender sobre o mundo e, sobretudo, com o mundo, eram inimagináveis para uma geração anterior. As tecnologias oferecem um convite engajador para que as pessoas interajam, se expressem, acessem o conhecimento e aprendam novas coisas através de uma forte dinâmica social. Também se configura um espaço de pesquisa para que possamos entender algumas mudanças comportamentais e culturais, principalmente no tocante ao 
que sabemos sobre como aprendemos e de como a tecnologia pode ser utilizada para estabelecer condições mais favoráveis à aprendizagem. Para avançar nestas questões devemos nos perguntar: como alguém pode ser preparado para enfrentar a complexidade trazida por esse mundo em constante mudança? A aprendizagem está mesmo ocorrendo na escola? como contribuir com a construção de diferentes tipos de inteligência? como o uso das tecnologias deve ser orquestrado para evitar que as pessoas se tornem ignorantes, visto que o acesso às informações tem sido cada vez mais fácil?

Este artigo apresenta uma série de considerações sobre os desafios da educação do futuro e do processo de aprendizagem na era digital. Discutiremos os elementos que caracterizam a nova cultura da aprendizagem, apontando situações que devem ser observadas para que os jovens possam atingir o seu potencial empreendedor de aprender. Apresentaremos essas considerações em duas seções. Na Seção 2 discutiremos a caracterização de uma cultura voltada para a aprendizagem. Na Seção 3 será discutido o papel das tecnologias nesse processo. Por fim, apresentamos as considerações finais.

\section{A cultura da aprendizagem}

Considerando que o processo formal de educação precisará se adequar para se tornar mais efetivo no desenvolvimento de novas competências nos indivíduos, temos que nos perguntar: que estímulos ou situações devem estar presentes nos ambientes de aprendizagem? Esta questão, por si só, apresenta uma mudança sutil no paradigma de escola a que estamos acostumados. A educação do futuro precisará se apoiar em um outro tipo de cultura, onde o ponto central deve ser a aprendizagem e não mais o ensino.

A escola de hoje ainda é pensada através de um modelo de fábrica (Barbosa, 2012), que padroniza o ensino para os estudantes e empacota os conteúdos que são entregues. A cultura da aprendizagem reposiciona esse modelo de escola em que o professor tem a função de repassar teorias abstratas aos seus alunos. É preciso possibilitar aos jovens criar coisas concretas, experimentar o mundo e ver $\mathrm{o}$ conhecimento escolar e científico fazerem parte da sua realidade. Na cultura da aprendizagem é importante mostrar às crianças como brincar com o conhecimento. Dessa forma, o estímulo à criatividade e à imaginação assume grande relevância nessa nova construção.

$\mathrm{Na}$ educação do futuro, o modelo de escola se ampara em uma abordagem de aprendizagem em que os estudantes se engajam com o mundo, o experimentam e o questionam a partir de elementos que são significativos. Isto significa que a construção dessa nova cultura entende a importância de substituir um modelo baseado na entrega de instrução por um modelo orientado à experimentação, algo que já era apresentado pela pedagogia de Montessori, que possuía como um dos seus principais valores a liberdade da criança agir através da sua interação com o mundo e pelas convicções de John Dewey (1954). Mais recentemente, Gee (2013) apresentou o conceito de circuito de ação reflexiva para ressaltar a relevância que a experimentação possui para a aprendizagem. Segundo ele, o circuito de ação reflexiva é um tipo de conversa que temos com o mundo. É, na verdade, uma sequência de experiências criadas no nosso imaginário, uma simulação de um instante da realidade, muito parecido com o que ocorre em jogos de videogame. Este processo se apresenta como algo altamente engajador para coisas que realmente nos importam. 
O processo de experimentar é algo que está relacionado intimamente com a dimensão tácita do conhecimento. A dimensão tácita foi apresentada por Michael Polanyi (1966), usa todos os sentidos e ocorre quando percebemos o conhecimento através de experiências individuais e coletivas. No mundo digital aprendemos fazendo, observando e experimentando. Exploramos, criamos conexões até aprender como algo funciona. Aprendemos com o processo, por vezes permeado de falhas, que também são uteis para que aumentemos a nossa pilha de conhecimentos. Como dizem Thomas e Brown (2011), o século XXI pertence ao tácito. Infelizmente, as técnicas e práticas que definem nossos modelos de aprendizagem se baseiam no conhecimento explícito. Não temos muitas teorias ou mecanismos para entender um mundo em constante mudança. Assim, a escola precisa compreender que ser capaz de capturar o conhecimento tácito será cada vez mais importante.

Outro aspecto importante é o fato de que a escola precisa compreender como transformar a aprendizagem em um jogo entre o conteúdo e o contexto. $\mathrm{O}$ ensino precisa romper os limites da sala de aula e chegar à família, à comunidade, assumindo, assim, uma natureza ecológica (Ito et al, 2013). Os jovens precisam de conexão e tradução entre a aprendizagem formal e aquela que ocorre fora da escola, fato que também é reforçado por Gee (2013). Todavia, o ensino escolar está desconectado desses outros contextos, se tornando, por vezes sem significado e desinteressante para os estudantes. Apesar dos conteúdos escolares serem pensados para que sejam uteis no cotidiano e no trabalho das pessoas, a percepção das conexões entre esses mundos nem sempre é tão evidente. Depois de um século de pesquisas sobre transferência, poucas evidências asseguram que o ensino desenvolve competências cognitivas gerais que são transferíveis para resolução de problemas fora da escola (NRC, 2012).

A cultura da nova aprendizagem valoriza o espírito empreendedor e a busca pela inovação nos ambientes de aprendizagem. A escola precisa estimular a criatividade e a imaginação dos jovens. Enquanto a criatividade pertence ao campo da solução, a imaginação pertence ao campo da problematização, da desconstrução. São processos complementares que nos levam ao exercício de empurrar as fronteiras do que conhecemos. Se não houver espaço na escola para tais elementos não haverá como desenvolver estudantes com potencial para a inovação e capazes de empreender no seu próprio processo de aprendizagem.

A educação do futuro precisa considerar potencialmente como aproveitar o que as pessoas podem aprender quando estão juntas, inseridas em espaços que valorizam os interesses comuns (Moser; Schnieder; de Medeiros, 2012). É através da colaboração que se pode criar um novo tipo de cultura onde os indivíduos estão engajados ativamente porque estão interessados em aprender algo lhes interessa. Isso reforça a percepção de que há muita aprendizagem acontecendo fora da sala de aula. É o que ocorre, por exemplo, nos blogs, com todo o seu potencial de produção de informação, cooperação e revisão e nas comunidades criadas para dar apoio aos jogadores multiusuários, como é o caso do que ocorre em vários jogos, onde milhares de informações são escritas em uma noite e boas estratégias são elaboradas coletivamente.

\section{O papel das tecnologias na educação do futuro}

$\mathrm{Na}$ era digital o papel das tecnologias será o de criar os meios necessários para que as relações com o coletivo ocorram. A tecnologia deve enriquecer a experiência das pessoas e permitir que os indivíduos compartilhem ideias. Neste contexto, é preciso 
entender a importância da Web como uma rede conectada, que nos dá acesso ilimitado para aprender sobre qualquer coisa.

Assim como ocorre com o cultivo de uma planta - onde recursos ilimitados, como sol, vento e terra - são utilizados dentro de um espaço restrito, a escola deve ser um ambiente de aprendizagem estruturado e com limitações, mas onde as pessoas possam experimentar com liberdade total e acesso aos recursos (livros, Web, recursos multimídia) dentro das fronteiras desse ambiente. Estas fronteiras devem funcionar não como algo limitador, mas como alguma coisa que desafie e estimule os jovens a serem criativos e inovadores. Assim, a escola deve aprender a cultivar mentes. Ito et al (2013) aponta que: i. as tecnologias são importantes porque fornecem oportunidades de produzir e criar uma ampla variedade de mídias, conhecimento e conteúdo cultural de maneira ativa e aberta à experimentação; ii. as mídias sociais e comunidades Web fornecem oportunidades para a aprendizagem entre diferentes culturas e gerações e uma conexão capaz de revelar e fazer florescer objetivos e interesses comuns e iii. as plataformas online e as ferramentas digitais tornam abundantes, acessíveis e visíveis muitos recursos de aprendizagem importantes para os estudantes.

O poder das tecnologias está no fato de que elas podem ser amplificadores da curiosidade, da experimentação e da autoexpressão. Há décadas a intuição de Montessori estava certa, mas o seu conjunto de ferramentas não era adequado, portanto, seus métodos não eram escaláveis. A infraestrutura tecnológica de que dispomos conecta as pessoas e amplifica a nossa capacidade de acessar e utilizar recursos ilimitados. Essa infraestrutura nos torna capazes de nos tornarmos produtores, não apenas consumidores do conhecimento. A maneira com que as pessoas estão aprendendo nessa revolução digital é diferente dos tipos de aprendizagem descritos pelos educadores porque ela é essencialmente invisível. As pessoas têm aprendido sem usar livros e professores e, mais importante, fora das fronteiras da sala de aula. Através da Internet e das suas ferramentas pode-se não só fazer as coisas, mas é possível refazer o contexto. Se podemos começar a criar novos contextos, temos toda uma nova dimensão para a criação de significado e para o ajuste das nossas lentes conceituais. Precisamos entender como uma abordagem educacional pode repensar o uso das mídias para que seja possível escalar, diversificar e expandir a amplitude das experiências, e não apenas utilizar as tecnologias na educação para reduzir os custos da "entrega" de conteúdo ou instruir de maneira que torne a aula mais prazerosa.

As tecnologias também podem ser utilizadas para suportar melhorias no processo de avaliação, entender o que o estudante é capaz de fazer e também, o que ele não é. Em publicação recente, Shute e Ventura (2013) demonstram uma metodologia de avaliação a partir de jogos invisível ao jogador. Ao brincar em um jogo que explora desafios, é possível medir o conhecimento sobre conceitos da física, fornecer feedback e o mais importante: identificar evidências que apontem a presença de algumas competências no comportamento dos jogadores, como é o caso de criatividade, persistência e originalidade aplicadas às soluções.

\section{Considerações finais}

O ritmo exponencial das mudanças tecnológicas tornará grande parte das habilidades que aprendemos na escola insuficientes. Podemos nos perguntar: os currículos escolares têm conseguido desenvolver competências que facilitem a nossa adaptação ao novo ou que nos tornem capazes de resolver problemas? O papel da escola terá mais a ver com 
tornar as pessoas capazes de se adaptar e a criar constantemente o novo, e menos com o de ensinar o velho. Para revigorar a escola não teremos que reformá-la, teremos que repensá-la com novos contextos e espaços de aprendizagem que se utilizem das tecnologias como mecanismo para que os estudantes estejam livres para criar, questionar e aprender com os colegas. Deveremos repensar o uso de tecnologias educacionais, dando prioridade à busca pela concepção de "espaços de aprendizagem e experimentação". Ensinar com o uso de tecnologias não se resumirá a verticalizar em uma tela de computador o que há nos livros. Significará potencializar o que nós humanos podemos ter de melhor quando estamos inseridos no coletivo.

Esse diferente exercício poderá fazer com que os alunos descubram seus interesses, suas paixões, e que estes se encontrem no universo dos conhecimentos escolares. Não se espera que a tarefa será fácil, mas, ao que tudo indica, será o melhor caminho que temos a seguir se realmente estivermos dispostos a fazer com que a escola possa contribuir para que os estudantes desenvolvam novos comportamentos e, consequentemente, as competências necessárias para um cidadão do século XXI. Este artigo apresenta uma revisão bibliográfica sobre os princípios da nova cultura de aprendizagem. O método que está conduzindo a pesquisa dos autores é de natureza qualitativa. Algumas teses e argumentos surgirão a partir da conceituação e da reflexão sobre este tema no cenário brasileiro. Dessa forma, este artigo é um trabalho preliminar a uma futura pesquisa-ação e representa um produto importante para que seja possível estabelecer um esboço conceitual para a realização de experimentos sob o apoio dos conceitos e premissas aqui consolidados.

\section{Referências}

Barbosa, H. H. (2012) Uma nova estética escolar: juntando os aspectos cognitivos e pedagógicos. Revista Educação e realidade. Vol.37, no.3. Porto Alegre, set - dez.

Dewey, J. (1954). Experience and education. The Kappa Delta Pi lecture series.

Gee, J. P. (2013) The Anti-Education Era: Creating Smarter Students through Digital Learning. Palgrave Macmillan. New York.

Ito, M., Gutiérrez, K., Livingstone, S., Penuel, B., Rhodes J., Salen, K., Schor, J., SoftonGreen, J., Watkins, S. C. (2013) Connected Learning: An agenda for Research and Design. Irvine, CA: Digital Media and Learning Research Hub.

Lopes, R. M. F.; Wendt, G. W.; Rathke, S. M.; Senden, D. A.; Da Silva, R. B. F.; Argimon, I. I. L. (2012) Reflexões teóricas e práticas sobre a interpretação da escala de inteligência Wechsler para adultos. Acta colombiana de psicologia; 15(2):109-118.

Moser, A., Schnieder, E. I., de Medeiros, L. F. (2012) A aprendizagem situada nas comunidades de prática: uma aproximação fenomenológica. Anais do XXIII Simpósio Brasileiro de Informática na Educação. Rio de Janeiro. Brasil.

National Research Council (2012) Education for Life and Work: Developing Transferable Knowledge and Skills in the 21st Century. Washington, D.C.

Polanyi, M. (1966) The tacit dimension. Garden City, NY: Doubleday.

Shute, V.; Ventura, M. (2013) Stealth assessment : measuring and supporting learning in video games. The John D. and Catherine T. MacArthur Foundation reports on digital media and learning. Massachusetts Institute of Technology Press books, 2013.

Thomas, D., Brown, J. S. (2011) A New Culture of Learning: Cultivating the Imagination for a World of Constant Change. CreateSpace Independent Publishing Platform. ISBN: 1456458884. 